\title{
Microstructure and Mechanical Properties of Heat-treated and Neutron Irradiated TRISO-ZrC Coatings
}

\author{
G. Vasudevamurthy ${ }^{a \dagger}$, Y. Katoh ${ }^{b}$, J. Aihara ${ }^{c}$, K. Sawa ${ }^{c}$ and L. L. Snead ${ }^{b}$ \\ ${ }^{a}$ High Temperature Materials Laboratory, Virginia Commonwealth University, Richmond, VA, USA \\ ${ }^{b}$ Materials Science \& Technology Division, Oak Ridge National Laboratory, Oak Ridge, TN, USA. \\ ${ }^{c}$ Japan Atomic Energy Agency, Ibaraki Ken, JAPAN.
}

\begin{abstract}
Six developmental sets of as-fabricated and heat-treated, near- and hyper-stoichiometric $\mathrm{ZrC}$ coated TRISO particles were subject to fast neutron $(E>0.1 \mathrm{MeV})$ fluences of 2 and $6 \times 10^{25}$ neutrons $/ \mathrm{m}^{2}$ at 800 and $1250{ }^{\circ} \mathrm{C}$ to assess the effects of irradiation on the coating microstructure and mechanical properties. Pre-irradiation microstructural analysis showed that the all but one of the near-stoichiometric samples fabricated by CVD had a homogenous grain structure while others including the hyper-stoichiometric sample had a distinct tiered band pattern with alternating carbon rich interlayers. The band structure in the near-stoichiometric samples became prominent following the heat treatment and the homogenous grained sample underwent severe grain growth. Post-irradiation observations indicated that neutron irradiation did not have any significant effects on the bulk microstructure of any of the samples regardless of the stoichiometry. Post-irradiation softening and reduction in modulus at the highest dose (6 dpa) were observed in all samples regardless of the composition and structure but were less significant in specimens with a banded microstructure. It was concluded that the carbon interlayers which contributed to the formation of the band structure had played a role in preserving the microstructure and the mechanical properties following both heat treatment and irradiation.

${ }^{\dagger}$ Corresponding Author

Email: gvasudev@vcu.edu

Phone: 804-828-3679 | Fax: (804) 827-7030
\end{abstract}




\subsection{Introduction}

Leading energy agencies around the world have endorsed the very high temperature reactor (VHTR) as the future face of nuclear power in order to meet the growing energy demand in addition to producing process heat for applications ranging from petrochemical refining to thermo-chemical hydrogen production [1]. The VHTRs are also to achieve burnup exceeding $200 \mathrm{GWd} / \mathrm{MTU}$ to ensure increased fuel utilization and waste reduction [1]. These specialized applications demand that VHTR fuels operate at temperatures as high as $1200^{\circ} \mathrm{C}$ and withstand transient temperatures of up to $1600^{\circ} \mathrm{C}$. Current alloys and metallic materials used in light water reactors do not satisfy these temperature requirements without significant changes in mechanical and physical properties. Ceramics such as silicon carbide (SiC) have been successfully employed in such extreme conditions [1]. These materials are proposed as mainly fission product barrier coatings and matrix in such applications.

A dispersion type fuel where conventional uranium dioxide fuel microspheres encapsulated in tiny individual barrier coatings dispersed and pelletized in an inert matrix (Figure 1) is the preferred fuel form for the proposed VHTRs [1-6]. The primary barrier coating has to successfully battle two extreme parameters: temperature and neutron bombardment without any significant detrimental changes in materials properties. Hence it is important to understand the effects of these on the microstructure and mechanical properties of this layer [1] before large scale deployment of these materials in such applications.

Zirconium Carbide ( $\mathrm{ZrC}$ ) has for long been proposed as an alternative to the currently used $\mathrm{SiC}$ on account of its higher melting point and comparable mechanical properties [2-4]. The most attractive feature of $\mathrm{ZrC}$ is its potential resistance to corrosion by fission product palladium as reported by Oagwa \& Ikawa [5]. However a majority in the nuclear fuel community agree that $\mathrm{ZrC}$ being a relatively less researched material for extreme environment applications requires intensive studies before being endorsed as a viable alternative to $\mathrm{SiC}$, primarily because of the challenges in controlling the composition (stoichiometry) of $\mathrm{ZrC}$ during coating fabrication and the lack of benchmarking data on the effects of composition on irradiation performance of $\mathrm{ZrC}$ [6]. Unlike $\mathrm{SiC}, \mathrm{ZrC}$ in known to exist in various stable carbon deficient (hypo-stoichiometric; $\mathrm{C} / \mathrm{Zr}<1.0$ ) and carbon rich (Hyper-stoichiometric; $\mathrm{C} / \mathrm{Zr}>1.0$ ) forms which add on a magnitude of complexity to this issue. If one observes the $\mathrm{Zr}-\mathrm{C}$ phase diagram, occurrence of perfect stoichiometric $\mathrm{ZrC}$ is represented by a very narrow range where even slight variations in 
processing parameters obviously could result in either hypo- or hyper - stoichiometric compositions [7]. Hence as a rule this change in stoichiometry is anticipated to result in corresponding changes in the microstructure, especially in the hyper-stoichiometric range where the material will have both $\mathrm{ZrC}$ and $\mathrm{C}$ phases [7]. Currently it is a matter open to debate, as to the issue of an optimal combination of stoichiometry and microstructure of $\mathrm{ZrC}$ that would be required for the coating to fulfill its intended function, primarily due to lack of benchmarking data on irradiation performance [6]. In course of several developments in coating technology, it has been observed that exercising exact control on $\mathrm{ZrC}$ coating composition during CVD runs is currently a major challenge [8-13], where even slight variations in process parameters such as: temperature, reactant mass flow or fluidizing gas flow rate, will inadvertently lead to deviation from perfect stoichiometry which in turn results in a different microstructure, even though the measured bulk stoichiometry may not noticeably vary. This resulting microstructure with the presence or absence of carbon is expected to have significant effects on the high temperature material properties such as mechanical strength and creep, although the nature of the effect is currently not well-known [6]. These excess carbon inclusions or precipitates and their structures may affect properties such as fracture toughness similar to alloys [6]. Hence it is required to carefully optimize the coating process to obtain a microstructural and compositional configuration that has the highest probability and potential to survive in a high temperature nuclear reactor environment without significant degradation in properties.

Neutron irradiation experiments on $\mathrm{ZrC}$ in the past have been limited by both material and experimental scope. Majority of the experiments have used samples prepared by powder metallurgical processes such as hot pressing, slip casting and explosion pressing [14-19]. Snead et al. [14] reported a review of historical irradiation experiments in addition to their recent work on zone refined $\mathrm{ZrC}_{0.93}$. Majority of these experiments have shown that neutron irradiation has no significant physical and microstructural effects on $\mathrm{ZrC}$. However a very few of these past experiments have employed the actual reactor grade CVD $\mathrm{ZrC}$ and hence the effects of irradiation on this particular genre of material is still not clearly established. The remaining few that have looked into the CVD $\mathrm{ZrC}$ have generally focused on specifics of fission product retention capability and integrity of the coatings as a whole and not actually dwelling on the material microstructure and mechanical property metamorphosis. 
In this context, the experiments and observations presented here assumes significance as it included four different microstructures with three variants within the near-stoichiometric composition and one within the hyper-stoichiometric composition, as currently it is not clear as to which combination of stoichiometry and microstructure works optimally and could potentially be standardized for $\mathrm{ZrC}$ coated TRISO fuels. One of the main goals of this experiment was to study the variation in irradiation response with varying microstructure and composition of $\mathrm{ZrC}$. The samples were irradiated in the High Flux Isotope Reactor (HFIR) at Oak Ridge National Laboratory followed by post irradiation microstructural characterization and measurement of elastic modulus and nano-hardness. The chosen maximum dose rate and the irradiation temperatures chosen for the experiments were close to half the anticipated life time dose $(\sim 6$ dpa) experienced by the actual coatings at the VHTR operating temperature $\left(\sim 1200{ }^{\circ} \mathrm{C}\right)$. These experiments were part of a larger co-operative research program between the US Department of Energy and the Japan Atomic Energy Agency (JAEA) to study the viability of developmental $\mathrm{ZrC}$ coating for nuclear fuel applications.

\subsection{Description of Experiments}

The developmental samples used in the irradiation experiment consisted of yttria-stabilized zirconia kernels coated with an inner pyrocarbon layer followed by a $\mathrm{ZrC}$ coating. Table 1 shows the experimental matrix. Some of the samples had an additional outer pyro-carbon layer, as indicated in Table 1. The details of the coating process and parameters are discussed in more detail in Aihara et. al. [9-11] and are outside the scope of the current work. The stoichiometry of the developmental coatings were measured by JAEA using bulk measurement techniques (electron x-ray diffraction and electron energy loss spectroscopy) and the nominal compositions were reported [11-13]. The experiments included the irradiation of two as-fabricated samples and four heat-treated samples as listed in Table 1. Out of the Six sample sets, samples ZC1HT, ZC2HT, ZC3HT and ZC4HT were derived from samples ZC1 ZC2, ZC3 and ZC4 after heattreating (hence the succeeding suffix HT) the respective as-fabricated samples at $\sim 1800{ }^{\circ} \mathrm{C}$ for 1 $\mathrm{h}$ to simulate the effect of heat-treating during a typical fuel compacting / pelletization process. Samples ZC1, ZC2 and ZC3 were all reported to have near-stoichiometric compositions (C/Zr 1.0) while ZC4 was reported to have a hyper-stoichiometric composition of $\mathrm{C} / \mathrm{Zr} \sim 1.4$. Samples ZC3 and ZC4 were excluded from the current irradiation experiments due to space constraints in 
the reactor. It is noted here irradiating the heat-treated samples was prioritized in this work as only they would have experienced the same conditions during heat treatment as the $\mathrm{ZrC}$ coatings that would actually be deployed in a VHTR following pelletization. Around fifty specimens from each of the sample sets were randomly selected for the irradiation experiment. Irradiation was performed in the flux trap facility of the High Flux Isotope Reactor (HFIR) at Oak Ridge National Laboratory (ORNL). The experiments were designed to irradiate the specimens at 800 and $1250{ }^{\circ} \mathrm{C}$ (nominal) to fast neutron fluences of 2 and $6 \times 10^{25}$ neutrons $/ \mathrm{m}^{2}(\mathrm{E}>0.1 \mathrm{MeV})$. After irradiation, the specimens were retrieved from the capsules and sorted in a hot cell at the ORNL's Irradiated Materials Examination and Testing (IMET) facility. Gamma spectroscopy was performed to identify the major activation products and the dose rates from the retrieved specimens were measured and subsequently transported to the Low Activation Materials Development and Analysis (LAMDA) Laboratory for post-irradiation examination (PIE). Representative specimens from each of the samples sets were gently cleaned in an ultrasonic bath and mounted in a two part epoxy resin. The cured specimen mounts were then ground using silicon carbide paper followed by stepwise polishing using polycrystalline diamond solutions using a Buehler minimet grinder and polisher. The metallographically prepared specimens were examined using JEOL 6500 field emission gun scanning electron microscope after coating them with thin carbon layers to make the mounts conductive. The micrographs were used to estimate the grain diameters using the ASTM E112 [20]. The nano-hardness and the elastic modulus were measured for all the specimens using an MTS Nano-indenter XP system at room temperature. A final depth limit of $500 \mathrm{~nm}$ was selected for all runs. Continuous stiffness measurement technique was employed for determining the elastic modulus of the specimens, using a Poisson's ratio of 0.2. Nano-indentation was performed on 5 different locations each, on two representative specimens belonging to a particular sample set to account for inter and intra specimen variations. The actual irradiation temperatures were measured by employing the resistivity measurement technique of post irradiation annealed SiC temperature monitors [22]. Measurements confirmed the irradiation temperatures to be close to 800 and $1250^{\circ} \mathrm{C}$.

\subsection{Results \& Discussions}

\subsection{As-fabricated and Heat-treated Samples}

\subsubsection{Microstructure}


Figure 2 shows the representative pre-irradiation microstructure of all the as-fabricated and heattreated samples used in the described experiments. It is noted here that the reason for more visible grain structure in the fine grained unirradiated specimens is due to etching by a diluted $10 \%$ hydrofluoric - $20 \%$ nitric acid mixture. However the irradiated specimens were not subject to etching due to handling issues.

Sample ZC1 showed very small grains $(<100 \mathrm{~nm})$ with no clear layered structure. The grains were homogenous and the micrograph showed a dense microstructure with the presence of very few voids, typical of a coating fabricated by the CVD process. Sample ZC1HT, produced by heat-treating ZC1 showed the presence of large grains $(>3 \mu \mathrm{m})$ in addition to some pores indicating large scale grain growth attributable to sintering and grain coalescence during the heat treatment phase. It was also evident that the grain growth had precipitated formation of voids.

The as-fabricated sample ZC2 showed a layered structure with very small grains along with some visible porosity. A higher magnification micrograph (Figure 3 (A)) showed alternating dark and bright bands indicating the presence of free carbon or carbon-rich layers between the $\mathrm{ZrC}$ layers, evidenced by the stark contrasts visible on backscattered electron micrographs. The higher magnification micrographs revealed no systematic or large scale porosity.

Sample ZC2HT, derived from sample ZC2 following heat treatment, showed the formation of fairly homogeneous grains due to the sintering process. Further, the average grain diameters (AGD) varied greatly from being $5 \mu \mathrm{m}$ near the inner and outer peripheries of the coating to $<1$ $\mu \mathrm{m}$ in the inner regions. The extent of grain growth in ZC2HT however was not the same as the extent of grain growth observed in ZC1HT indicating that large scale grain growth was inhibited albeit both ZC1 and ZC2 were nominally stoichiometric compositions. The region close to the IPyC-ZrC layer interface contained finer grains compared to the region close to the outer periphery. This conclusion is further supported by the micrograph (Figure 3(B)) of sample ZC3 (not irradiated in this experiment). This as-fabricated predecessor of sample ZC3HT shows a clear layered structure in the inner regions which had been retained during heat treatment. Postheat treatment, the inner region with finer grains had undergone growth on a smaller scale compared to the outer layer as visible from the micrographs. This anomaly could be attributed to the presence of carbon-rich layers between the stoichiometric $\mathrm{ZrC}$ layers in the inner region which could be distinguished as dark inclusion layers in back scattered electron images. This hypothesis was confirmed from the microstructural observations of the known hyper- 
stoichiometric sample ZC4HT. The microstructure of this sample revealed a ring structure with alternating dark and bright annular bands similar to, but more conspicuous and clear compared to sample ZC2HT. The dark bands represented the excess carbon or carbon-rich layers, while the bright bands represented small $\mathrm{ZrC}$ grains $(\sim 100 \mathrm{~nm})$. The presence of carbon-rich layers was also confirmed by JAEA while reporting the transmission electron microscope observations of the heat-treated samples of ZC4HT [9- 11]. The presence of this carbon interlayer had inhibited grain growth in sample ZC4HT during heat treatment. Hence although samples ZC2HT and ZC3HT were expected to have nominal stoichiometric compositions, it was clear that the inner region of sample ZC3HT and all of ZC2HT had carbon-rich layers deposited between the coating layers, which had resulted in stunted grain growth following the heat treatment. It is noted here that the perfect stoichiometric $\mathrm{ZrC}$ only occurs in an extremely narrow region of the $\mathrm{Zr}-\mathrm{C}$ phase diagram thus making it difficult to achieve such an ideal composition [7]. Even a slight excess or deficit in carbon content, attributable to inadvertent errors associated with bulk fabrication will indeed push the final product into either above or below the ideal stoichiometric region, understandably well below the limits of bulk compositional analysis techniques [7, 9-11]. However in the current experiment, this phenomenon was considered desirable making it arguably beneficial in the study of dependence of irradiation response on the microstructure and composition resulting from such bulk fabrication runs [9-11].

\subsubsection{Mechanical Properties}

The results of the nano-indentation measurements on the as-fabricated and heat-treated samples are summarized in Table 2. A comparison of the nano-hardness and elastic modulus indicated that, with grain growth resulting from heat treatment, the nano-hardness and modulus decreased with the percentage reduction ranging between 3 and $14 \%$. As expected the nominally stoichiometric samples exhibited a higher nano-hardness and modulus than the hyperstoichiometric ZC3HT sample which could be clearly attributed to the presence of known excess carbon in this sample.

Further, a quick comparison of average nano-hardness values of heat-treated samples indicates that the nano-hardness of ZC3HT and ZC2HT lies roughly between those of ZC1HT and ZC4HT, further solely attributable to the carbon-rich interlayers albeit they were nominally stoichiometric compositions. This was further evidenced by slight reduction in the measured 
moduli of ZC2HT and ZC3HT in comparison with ZC1HT. However, it is noted here that the results of the nano-indentation as applicable to the nominally stoichiometric samples have to be interpreted conservatively since the exact position of the indentation (relative to the center of the grain) cannot be controlled in materials with fine grain structures such as the ones used in the current experiments. The data is also expected to deviate on account of the substrate effects in thin samples. The nano-hardness of $\mathrm{ZrC}$ is also known to be dependent on the crystallographic orientation [20] which can become significant in small grained samples. Figure 4 shows the variation of nano-hardness with the $\mathrm{C} / \mathrm{Zr}$ ratio, as reported by $\mathrm{He}$ et al. for $\mathrm{ZrC}$ thin films [21] with additional data points from the current work. The nominal C/Zr ratios reported by JAEA were used to plot the data points from the current work. It is seen in the plot that the nanohardness of $\mathrm{ZrC}$ reaches a maximum in the slightly carbon deficit range $(\mathrm{C} / \mathrm{Zr} \sim 0.8$ to 1.0 , hypostoichiometric composition) and decreases with increasing carbon content. As mentioned in the experimental section, indentations were carried out at various locations ( 5 different locations on two representative specimens belonging to each sample lot), to account for some of these variations and extend further credibility to the measured values.

\subsection{Irradiated Samples}

\subsubsection{Microstructure}

Observations of sample $\mathrm{ZC1}$ revealed no significant change from the pre-irradiation microstructure, with no noticeable change in the AGD or porosity. Although some microcracks were observed close to the IPyC layer, they could not be clearly attributed to irradiation and could be artifacts of the specimen preparation.

Micrographs of sample ZC1HT (Figure 5) indicated no drastic changes in the microstructure compared to the pre-irradiation microstructure. Qualitatively only a modest grain growth (based on AGD) was observed, especially in the inner layers close to the $\mathrm{ZrC}$-IPyC interface in samples irradiated to $6 \mathrm{dpa}$. Most of the porosity in these samples appeared to have resulted from coalescence of grains, commonly observed during heat treatment and were possibly preserved during irradiation. The extent of porosity evolution during irradiation was unclear.

Microstructural observations of sample ZC2 irradiated at 2 and 6 dpa showed grain growth similar to the inner region of ZC3HT. Sample ZC2HT (Figure 6) showed the preservation of preirradiation porosity with a modest (in comparison to ZC1HT) grain growth similar to the 
irradiation induced grain growth in the inner region of sample ZC3HT. The irradiated microstructure of sample ZC3HT (Figure 7) revealed a preserved pre-irradiation two region layered structure. Grain growth phenomenon similar to ZC1HT was observed in these samples and was more clearly visible in samples irradiated to $2 \mathrm{dpa}$ at $800^{\circ} \mathrm{C}$. Grain growth in most of the annular bands of the inner regions, which had carbon-rich layers between them, appeared to be on a much smaller scale, except in areas in the immediate vicinity of the IPyC-ZrC interface. A comparison of the AGD indicated that the overall grain growth in ZC3HT specimens was much less compared to ZC1HT specimens (Figure 9). This could be attributed to the carbon /carbonrich interlayers which had inhibited large scale grain growth.

The microstructure of sample ZC4HT (Figure 8) did not show any noticeable changes in terms of grain growth or formation of porosity. The carbon-rich layer between the $\mathrm{ZrC}$ layers had clearly suppressed grain growth in these samples during irradiation. ZC4HT samples retained the preirradiation layered structure.

The measured AGD of the three heat-treated, nominally stoichiometric specimens is given in Figure 9. The AGD for the as-fabricated, nominally stoichiometric specimens (ZC1, ZC2) and the heat-treated, hyper-stoichiometric ZC4HT did not show any reportable changes as they all stayed well within the original sub-micron ranges $(100-200 \mathrm{~nm})$. It is noted here that the observed modest grain growths in ZC1HT, ZC2HT and ZC3HT can be attributed to a combination of both irradiation (a-thermal) and thermal effects (higher doses and irradiation temperatures). Albeit irradiation assisted (a-thermal) grain growth has been reported in various nano-crystalline materials (especially thin films) subject to ion irradiation [22], no such phenomenon has been reported in zirconium carbide and hence can only be speculated till further confirmatory studies are performed.

\subsubsection{Mechanical Properties}

The results of the nano-indentation tests on the irradiated samples are listed in Table 2. Postirradiation measurements indicated that the nano-hardness and modulus had decreased in asfabricated samples and heat-treated samples with a layered structure especially at the highest dose of 6 dpa and only modest at 2 dpa falling well within the experimental standard deviations of the values reported for unirradiated specimens. Figures 10 and 11 show the measured changes in nano-hardness and modulus in the samples, respectively. 
These measurements are somewhat in contrast to the observations reported in the literature. Irradiation experiments reported by Andreivskii [18], Koval'chenko [19], and Snead [12] have all reported a 10-15\% increase in modulus and hardening in contrast to the ones measured in the current experiment. However it is noteworthy that none of the previously reported experiments involved prototypical CVD ZrC nor did they employed doses as high as $6 \mathrm{dpa}$, which in part may explain the contrasting observations. This softening if consistent, can be argued as beneficial to a certain extent under scenarios where the nuclear fuel kernel anisotropically deforms and exerts highly localized stresses on the coatings [23]. A certain leeway in the coating's local plastic deformability (hardness) will perhaps help in negating the harmful effects of such concentrated stresses.

The as-fabricated sample ZC1 appeared to have softened the most, especially at the highest irradiation dose (6 dpa). Sample ZC1 showed a total change of $\sim 68 \%$ in the average nanohardness and $\sim 50 \%$ in the modulus. This anomaly could not be explained fully as the microstructure did not reveal any noticeable changes such as large scale micro-cracks or grain growth. Although other possible causes such as micro-texture development in small grained samples are known to reduce the nano-hardness, no effort to characterize them was made under the current experiment. This particular phenomenon of limited plastic deformation at high temperatures in near stoichiometric $\mathrm{ZrC}$ has been discussed by Darolia and Archbold [24] and perhaps makes $\mathrm{ZrC}$ more unique than the traditionally employed SiC coatings, which may help to relieve highly localized stresses. A careful investigation of the raw data indicated highly consistent and repeatable measurements putting to rest any speculation on changes in test setup or the parameters during the measurements although a possible interfering substrate effect could not be categorically ruled out. Sample ZC2 irradiated to 6 dpa showed $\sim 16 \%$ reduction in average nano-hardness and $\sim 17 \%$ reduction in the average modulus.

The reduction in both modulus and nano-hardness in the heat-treated samples were comparatively lower than the as-fabricated samples. However, majority of them exhibited a similar trend, where the nano-hardness decreased noticeably with increasing dose. Sample ZC1HT, where a homogenous grain structure was observed, had the least reduction in nanohardness and modulus at the highest dose. The changes in average nano-hardness and modulus were a modest $2.5 \%$ and $2.8 \%$, respectively falling well within the known experimental errors (standard deviation of un-irradiated samples). The measurements on ZC1HT were more in line 
with the ones reported in the literature indicating the near stoichiometric composition of the samples.

Although evolution of pores, texture and microcracks may be construed as possible causes for this drastic reduction, microstructural observations did not bare evidence to this phenomenon on a large scale as predicted by these measurements. For reasons discussed in the earlier sections slight variation in the measured values for small grained samples are expected due to lack of any particular order of orientation. It is also suspected that the $6 \mathrm{dpa}$ irradiation temperature $\left(1250^{\circ} \mathrm{C}\right)$ falling within the range of $\mathrm{ZrC}$ ductile to brittle transition temperature $\left(1200-1300^{\circ} \mathrm{C},[6,21]\right)$ may have had an effect on the nano-hardness and modulus.

The reduction in the nano-hardness and the modulus can at best only speculated to have occurred due to a phenomenon similar to irradiation assisted recovery leading to softening observed in steels [25]. This explanation although could possibly be tied to the observed post-irradiation grain growth in the heat-treated specimens, the drastic changes observed in nano-hardness and modulus cannot be wholly attributed to recovery. It is also noteworthy here that all samples except ZC4HT being nominally stoichiometric, perhaps tending more towards the hypostoichiometric range $(\mathrm{C} / \mathrm{Zr}<1.0)$, where the material can be expected [25] to exhibit susceptibility to a phenomenon similar to thermal aging and loss of strength due to creep at higher irradiation temperatures similar to the softening effects of heat treatment which may have had some (bulk) effects on the observed reduction of modulus and nano-hardness. It is expected that further investigations using other characterization tools, such as transmission electron microscopy to observe the defect structure and texture analysis using electron back scattering diffraction could possibly link the microstructural changes with these measurements and address the observed anomalies.

\subsection{Conclusions}

\subsection{As-fabricated and Heat-treated Samples}

Samples with as-fabricated non-layered (homogeneous) microstructure experienced severe grain growth during heat treatment by grain coalescence, whereas samples with as-fabricated layered microstructure exhibited much smaller degree of grain growth. This is attributed to the presence of carbon-rich layers deposited between the $\mathrm{ZrC}$ layers during fabrication. The role of the carbon-rich layer in inhibiting grain growth was confirmed during subsequent microstructural 
observations of the known carbon-rich ZC4HT samples, which indicated no significant grain growth after heat treatment.

The study also revealed the high sensitivity of the microstructure to potential shifts in stoichiometry that were not apparent during bulk compositional measurements nor the asfabricated microstructure or the pre-irradiation hardness and modulus measurements, but were surprisingly very prominent after the heat treatment. This again can be traced back to the occurrence of perfect stoichiometric $\mathrm{ZrC}$ over an extremely narrow range on the $\mathrm{Zr}-\mathrm{C}$ phase diagram in addition to the limitations of bulk composition measurement techniques. This further confirms the challenge in fabricating standardized $\mathrm{ZrC}$ coatings for TRISO applications.

In the unirradiated samples, the nano-hardness and modulus of stoichiometric $\mathrm{ZrC}$ decreased with the grain growth resulting from heat treatment. The nano-hardness and modulus of coatings with a banded structure also reduced which was in part attributed to the presence of relatively softer carbon-rich layers between coating interlayers, softening the bulk material.

\subsection{Irradiated Samples}

Samples with a nominal stoichiometric compositions (heat-treated) had undergone grain growth that could at present only be best described as modest. The effects of irradiation in some of the regions were similar to carbon-rich $\mathrm{ZrC}(\mathrm{ZC} 4 \mathrm{HT})$. The stunted grain growth observed in some of the regions is attributed to the presence of carbon-rich interlayers. Although there was evidence of large pores in some of the irradiated samples, it was unclear if the pores had originated during heat treatment or irradiation as no quantitative analysis was possible.

The nano-hardness and modulus decreased in irradiated samples irrespective of their composition or homogeneity at the highest applicable dose ( $6 \mathrm{dpa})$. This softening can be argued as beneficial to a certain extent under scenarios where the nuclear fuel kernel anisotropically deforms during operation under the influence of anisotropic thermal gradients and exerts stresses on the coatings [24]. A certain leeway in the coating's local plastic deformability will perhaps help in negating the harmful effects of such localized stresses. However the lower limits to reduction in moduli and nano-hardness have to be determined by in-core experiments involving actual uranium based fuel kernels, so as to not degrade the mechanical properties to a level that can be catastrophic to the coating's barrier function. 
Barring one sample (ZC2), the reduction in nano-hardness and moduli were not as noticeable in samples irradiated to $2 \mathrm{dpa}$. The as-fabricated sample $\mathrm{ZC1}$ exhibited the largest change in modulus and nano-hardness especially at higher doses and temperatures, partially attributed to irradiation induced recovery although the corresponding grain growth levels in these specimens could not be directly correlated to the observed drastic decrease in the modulus and hardness. The heat-treated sample ZC1HT showed the least change in modulus and nano-hardness at the highest dose (6 dpa). The reduction in nano-hardness and modulus of all specimens, at best can be speculated to arise from irradiation induced recovery and thermal ageing effects. However further dedicated studies will be required to confirm the phenomenon.

In conclusion, albeit no significant changes at lower doses were observed in all the samples irrespective of stoichiometry or the microstructure, it is believed that near-stoichiometric $\mathrm{ZrC}$ coatings with a layered structure with carbon-rich interlayers (thus a slightly hyperstoichiometric composition) resembling those of ZC2 and ZC3 are expected to have a better microstructural and mechanical response to irradiation at high doses and applicable temperatures. Another noteworthy point was the observed paths of the micro-cracks in samples. Although the origin of the micro-cracks seen on the electron micrographs were unclear (irradiation/handling/metallographic prep), the cracks in the layered samples seemed to propagate circumferentially rather than radially, a phenomenon if scientifically verified could further strengthen the case for a coating with layered structure. Tests to verify the crack propagation phenomenon are currently underway and hence has only been very briefly mentioned.

\section{Acknowledgements}

The work and results reported here were supported under the aegis of US Department of Energy's Advanced Gas Reactor Program and the International Nuclear Energy Research Initiative of which the Japan Atomic Energy Agency was a primary scientific partner of the Oak Ridge National Laboratory. The authors also wish to acknowledge the ORNL SHARE program for providing the required scanning electron microscope employed in microstructural characterization. 
Table 1. Sample Matrix and Irradiation Conditions

\begin{tabular}{|c|c|c|c|c|c|}
\hline $\begin{array}{l}\text { Sample Lot } \\
\text { (ORNL) }\end{array}$ & JAEA Nomenclature & $\mathrm{IPyC} / \mathrm{OPyC}$ & $\begin{array}{l}\text { Bulk C/Zr } \\
\text { (Nominal) }\end{array}$ & $\begin{array}{l}\text { Dose } \\
\text { (dpa) }\end{array}$ & $\mathrm{T}_{\mathrm{irr}}\left({ }^{\circ} \mathrm{C}\right)$ \\
\hline \multirow[t]{2}{*}{$\mathrm{ZC} 1$} & \multirow[t]{2}{*}{ ZrC-07-3002 } & \multirow[t]{2}{*}{ Yes/Yes } & \multirow[t]{2}{*}{1.0} & 2 & $\begin{array}{l}800 \\
1250\end{array}$ \\
\hline & & & & 6 & 1250 \\
\hline \multirow[t]{2}{*}{ ZC1HT } & \multirow[t]{2}{*}{ ZrC-07-3002HT } & \multirow[t]{2}{*}{ Yes/Yes } & \multirow[t]{2}{*}{1.0} & 2 & $\begin{array}{l}800 \\
1250\end{array}$ \\
\hline & & & & 6 & 1250 \\
\hline \multirow[t]{2}{*}{$\mathrm{ZC} 2$} & \multirow[t]{2}{*}{ ZrC-07-3010 } & \multirow[t]{2}{*}{ Yes/Yes } & \multirow[t]{2}{*}{1.0} & 2 & $\begin{array}{l}800 \\
1250\end{array}$ \\
\hline & & & & 6 & 1250 \\
\hline \multirow[t]{2}{*}{ ZC2HT } & \multirow[t]{2}{*}{ ZrC-07-3010HT } & \multirow[t]{2}{*}{ Yes/Yes } & \multirow[t]{2}{*}{1.0} & 2 & $\begin{array}{l}800, \\
1250\end{array}$ \\
\hline & & & & 6 & 1250 \\
\hline \multirow[t]{2}{*}{ ZC3HT } & \multirow[t]{2}{*}{ ZrC-06-2048HT } & \multirow[t]{2}{*}{ Yes/No } & \multirow[t]{2}{*}{1.0} & 2 & $\begin{array}{l}800, \\
1250\end{array}$ \\
\hline & & & & 6 & 1250 \\
\hline \multirow[t]{2}{*}{ ZC4HT } & \multirow[t]{2}{*}{ ZrC-06-2003HT } & \multirow[t]{2}{*}{ Yes/No } & \multirow[t]{2}{*}{1.4} & 2 & $\begin{array}{l}800, \\
1250\end{array}$ \\
\hline & & & & 6 & 1250 \\
\hline
\end{tabular}


Table 2. Results of Nano-indentation on irradiated specimens

\begin{tabular}{|c|c|c|c|c|c|c|c|c|c|}
\hline $\begin{array}{c}\text { Sample } \\
\text { Lot }\end{array}$ & $\begin{array}{l}\mathbf{T}_{\text {irr }} \\
\left({ }^{\circ} \mathbf{C}\right)\end{array}$ & $\begin{array}{l}\text { Irradiation } \\
\text { Dose } \\
\text { (dpa) }\end{array}$ & $\begin{array}{c}\mathbf{A G D}^{\dagger} \\
(\mu \mathrm{m})\end{array}$ & Hardness & $\begin{array}{c}\text { Std Dev. } \\
\text { (Hardness) }\end{array}$ & $\begin{array}{c}\text { Change } \\
\text { in } \\
\text { Hardness } \\
(\%)\end{array}$ & $\begin{array}{c}\text { Modulus } \\
\text { (GPa) }\end{array}$ & $\begin{array}{l}\text { Std Dev. } \\
\text { (Modulus) }\end{array}$ & $\begin{array}{l}\text { Change } \\
\text { in } \\
\text { Modulus } \\
(\%)\end{array}$ \\
\hline \multirow{4}{*}{ ZC1 } & Unirr & - & 0.1 & 29.9 & 0.93 & - & 350.5 & 21.11 & - \\
\hline & 800 & 2 & 0.1 & 27.1 & 2.65 & 9.4 & 304.3 & 30.21 & 13.2 \\
\hline & 1250 & 2 & 0.1 & 27.3 & 1.55 & 8.7 & 332.1 & 12.14 & 5.2 \\
\hline & 1250 & 6 & 0.1 & 9.51 & 1.38 & 68.2 & 177.6 & 13.52 & 49.3 \\
\hline \multirow{4}{*}{ ZC1HT } & Unirr & - & 3.96 & 28.1 & 2.95 & - & 341.7 & 17.84 & - \\
\hline & 800 & 2 & 4.2 & 26.9 & 5.01 & 4.3 & 339.1 & 46.36 & 0.8 \\
\hline & 1250 & 2 & 4.6 & 25.5 & 1.51 & 9.2 & 271.5 & 11.22 & 20.5 \\
\hline & 1250 & 6 & 4.4 & 27.4 & 4.00 & 2.5 & 332.2 & 24.60 & 2.8 \\
\hline \multirow{4}{*}{$\mathrm{ZC2}$} & Unirr & - & 0.1 & 29.2 & 0.83 & - & 366.5 & 7.39 & - \\
\hline & 800 & 2 & 0.1 & 24.3 & 2.09 & 16.8 & 292.6 & 10.80 & 20.2 \\
\hline & 1250 & 2 & 0.1 & - & - & - & - & - & - \\
\hline & 1250 & 6 & 0.1 & 24.5 & 2.44 & 16.1 & 302.2 & 16.97 & 17.5 \\
\hline \multirow{4}{*}{ ZC2HT } & Unirr & - & 0.9 & 24.9 & 1.73 & - & 340.6 & 18.75 & - \\
\hline & 800 & 2 & 1.12 & 25.9 & 1.89 & -4.0 & 317.5 & 11.09 & 6.8 \\
\hline & 1250 & 2 & 1.16 & 27.7 & 1.71 & -11.2 & 352.0 & 15.30 & -3.3 \\
\hline & 1250 & 6 & 1.32 & 21.3 & 1.45 & 14.5 & 290.2 & 8.84 & 14.8 \\
\hline \multirow{4}{*}{ ZC3HT } & Unirr & - & 2.33 & 25.9 & 2.05 & - & 327.9 & 13.96 & - \\
\hline & 800 & 2 & 2.46 & 25.9 & 1.11 & 0.0 & 315.8 & 8.895 & 3.7 \\
\hline & 1250 & 2 & 3.1 & 25.2 & 2.37 & 2.7 & 325.0 & 14.41 & 0.9 \\
\hline & 1250 & 6 & 3.19 & 19.4 & 2.28 & 25.1 & 262.8 & 16.50 & 19.9 \\
\hline \multirow{4}{*}{ ZC4HT } & Unirr & - & 0.2 & 18.6 & 0.56 & - & 240.2 & 11.85 & - \\
\hline & 800 & 2 & 0.2 & 18.4 & 1.43 & 1.1 & 196.7 & 12.04 & 18.1 \\
\hline & 1250 & 2 & 0.2 & 17.7 & 1.13 & 4.8 & 224.8 & 9.07 & 6.4 \\
\hline & 1250 & 6 & 0.2 & 14.4 & 1.93 & 22.6 & 197.9 & 40.18 & 17.6 \\
\hline
\end{tabular}

* Change measured using respective unirradiated values as reference.

${ }^{\dagger}$ Reported AGDs for specimens ZC1, ZC2 and ZC4HT are nominal values only owing to the potential errors in measuring sub-micron grain diameters using electron micrographs 


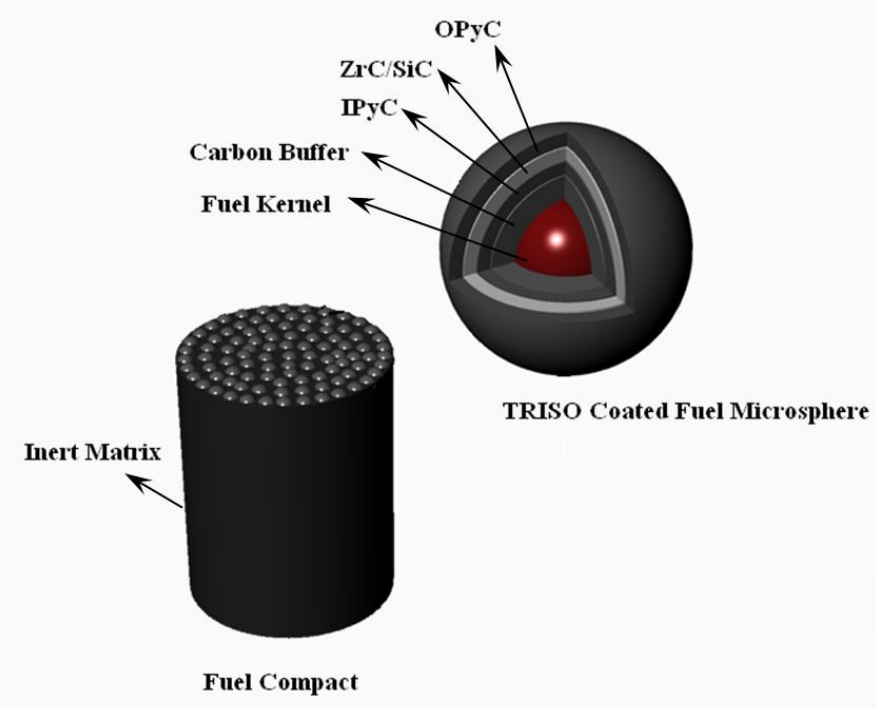

Figure 1. TRISO fuel for VHTRs 


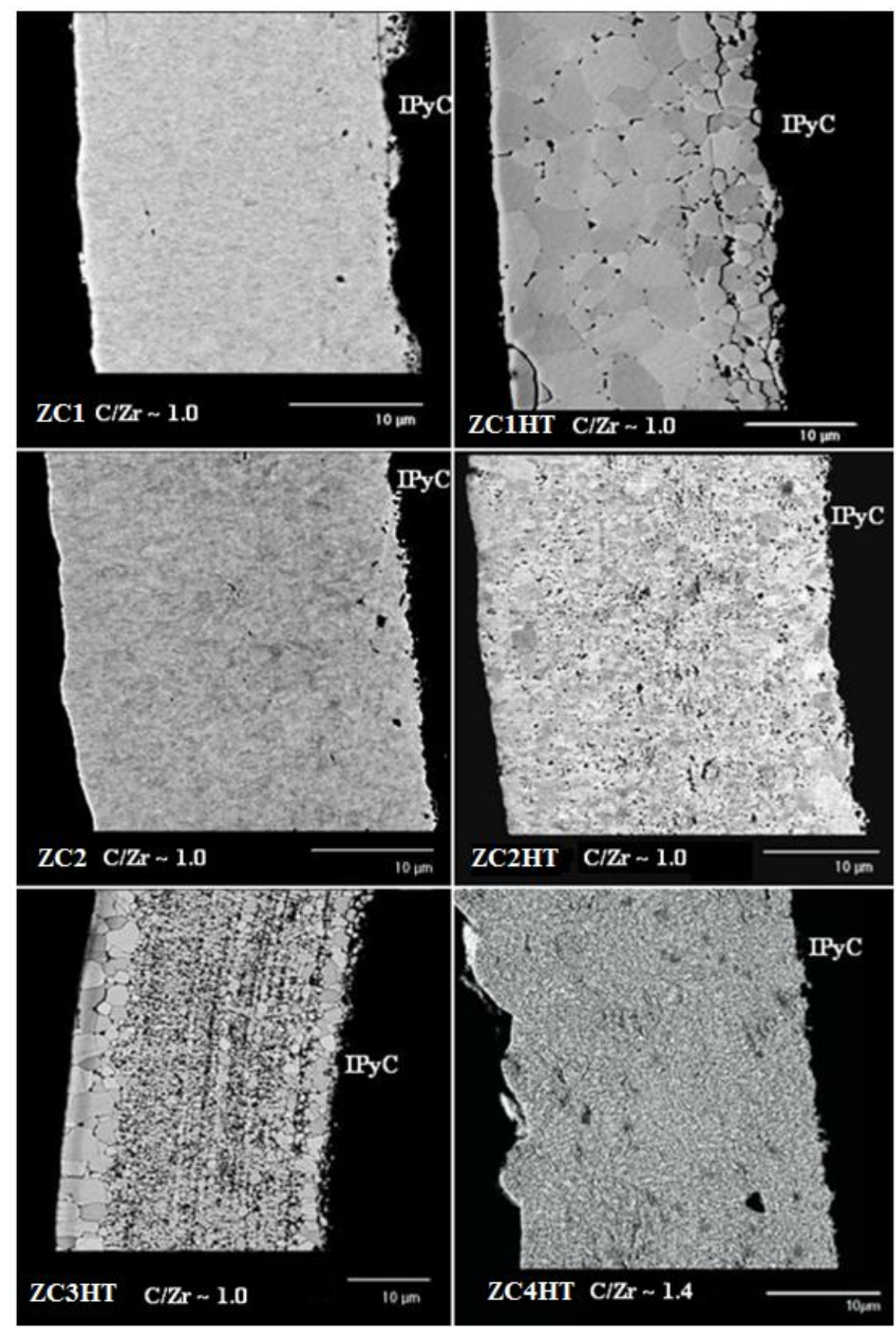

Figure 2. Pre-irradiation microstructures of the six set of CVD ZrC samples, some with HT suffixes used to indicate heat treatment at $1800{ }^{\circ} \mathrm{C}$ for $60 \mathrm{mins}$ 

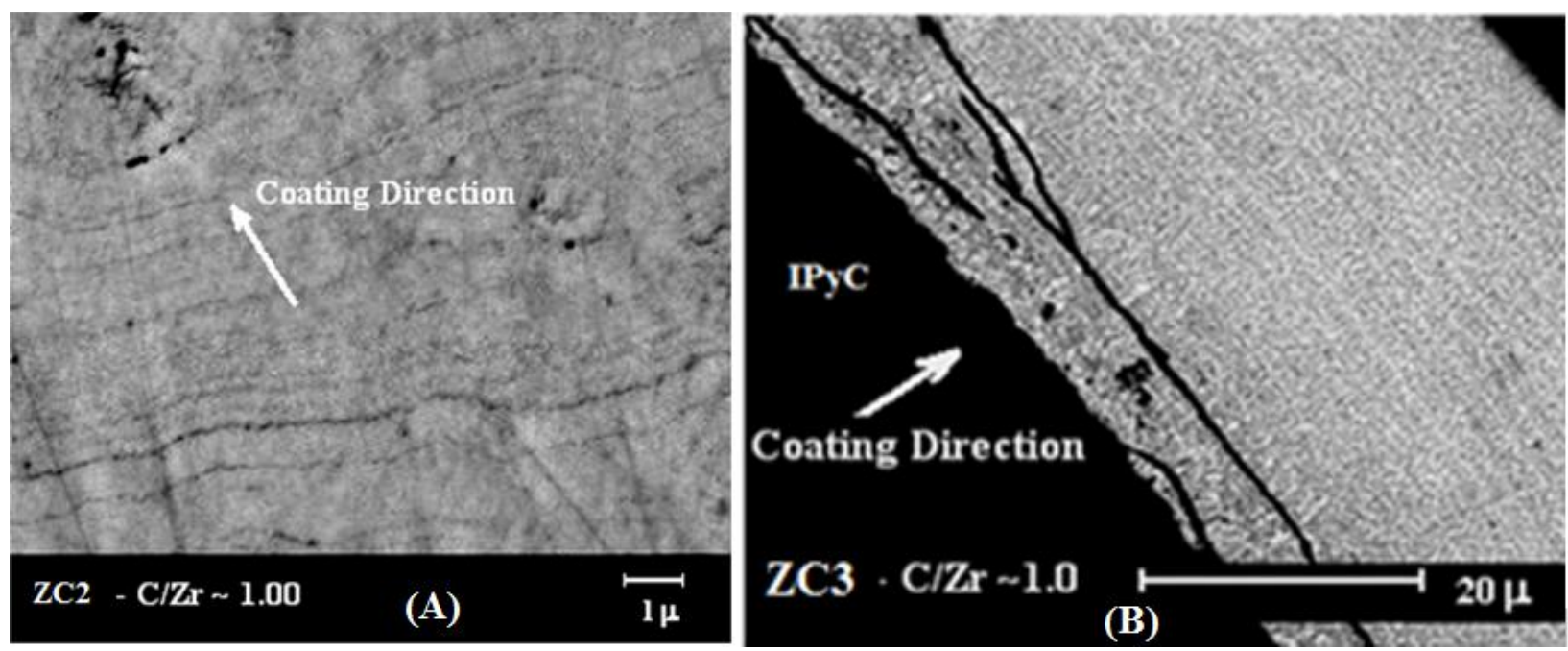

Figure 3. As-fabricated microstructure of ZC2 (A) and ZC3 (B) showing nano-sized grains with a layered structure (nominal $\mathrm{C} / \mathrm{Zr}=1.0)$

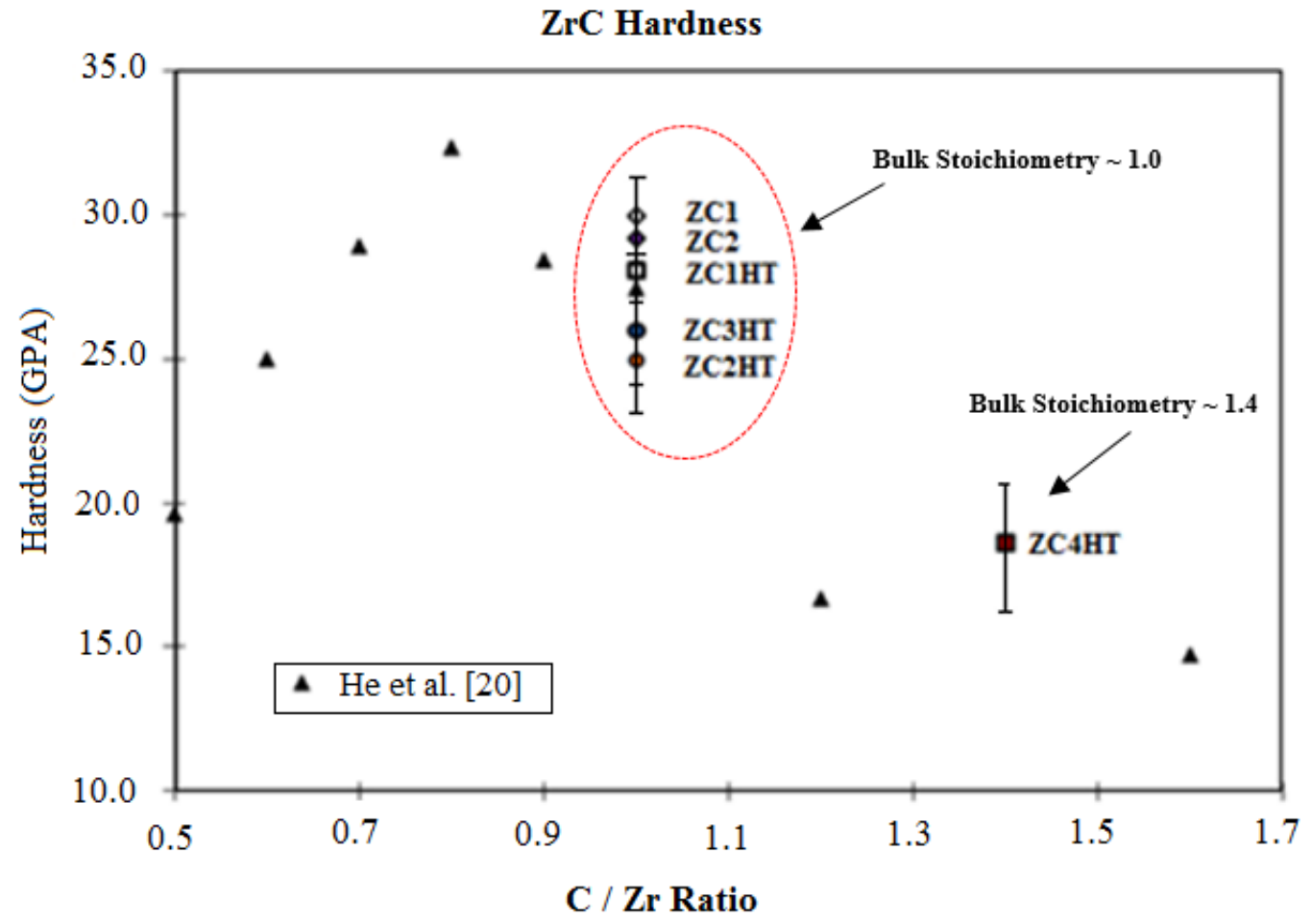

Figure 4. Variation of nano-hardness of $\mathrm{ZrC}$ with $\mathrm{C} / \mathrm{Zr}$ ratio 

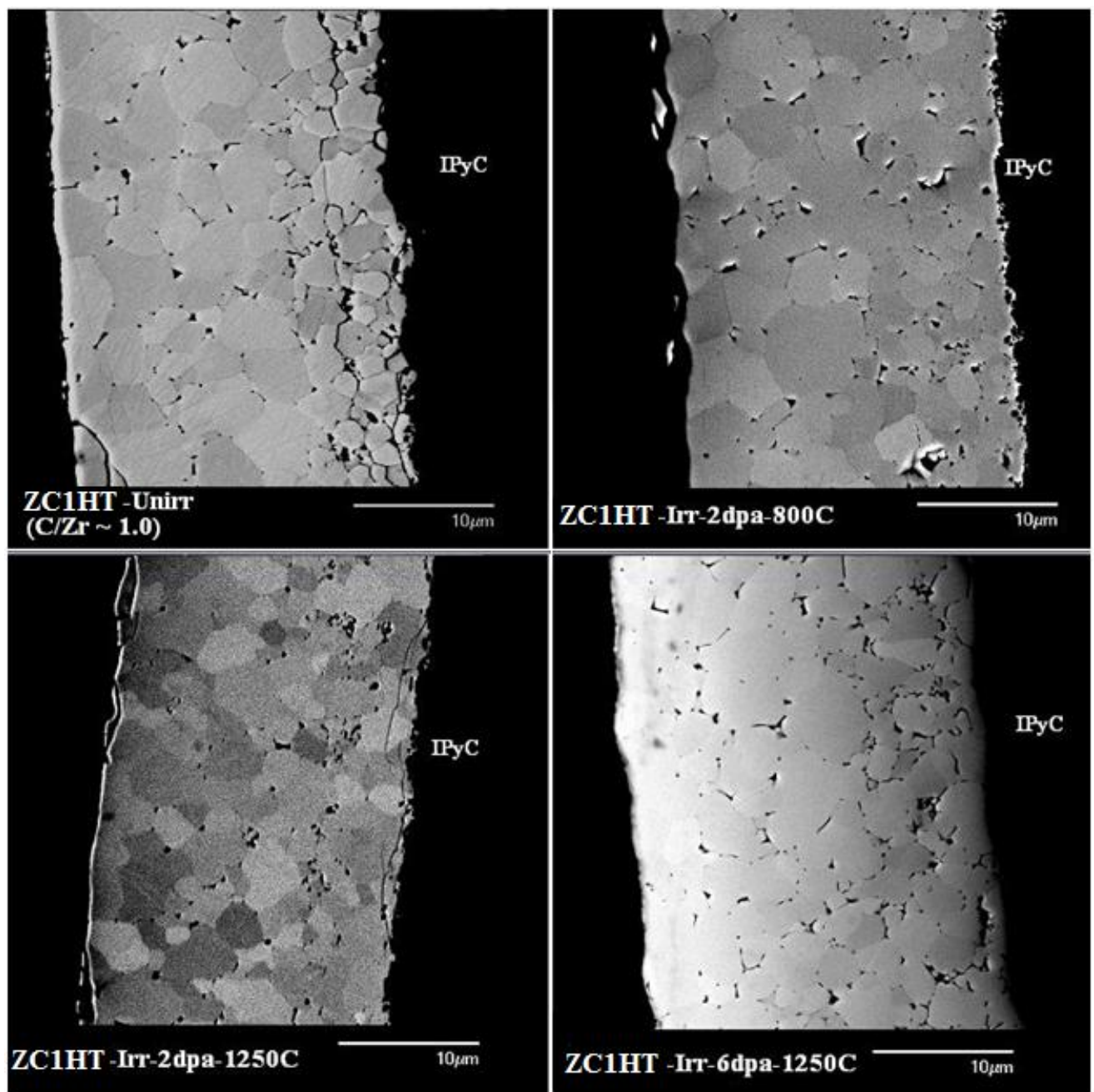

Figure 5. Pre- and post-irradiation microstructure of sample ZC1HT $(\mathrm{C} / \mathrm{Zr} \sim 1.0)$ showing modest grain growth especially at higher dose and irradiation temperatures 


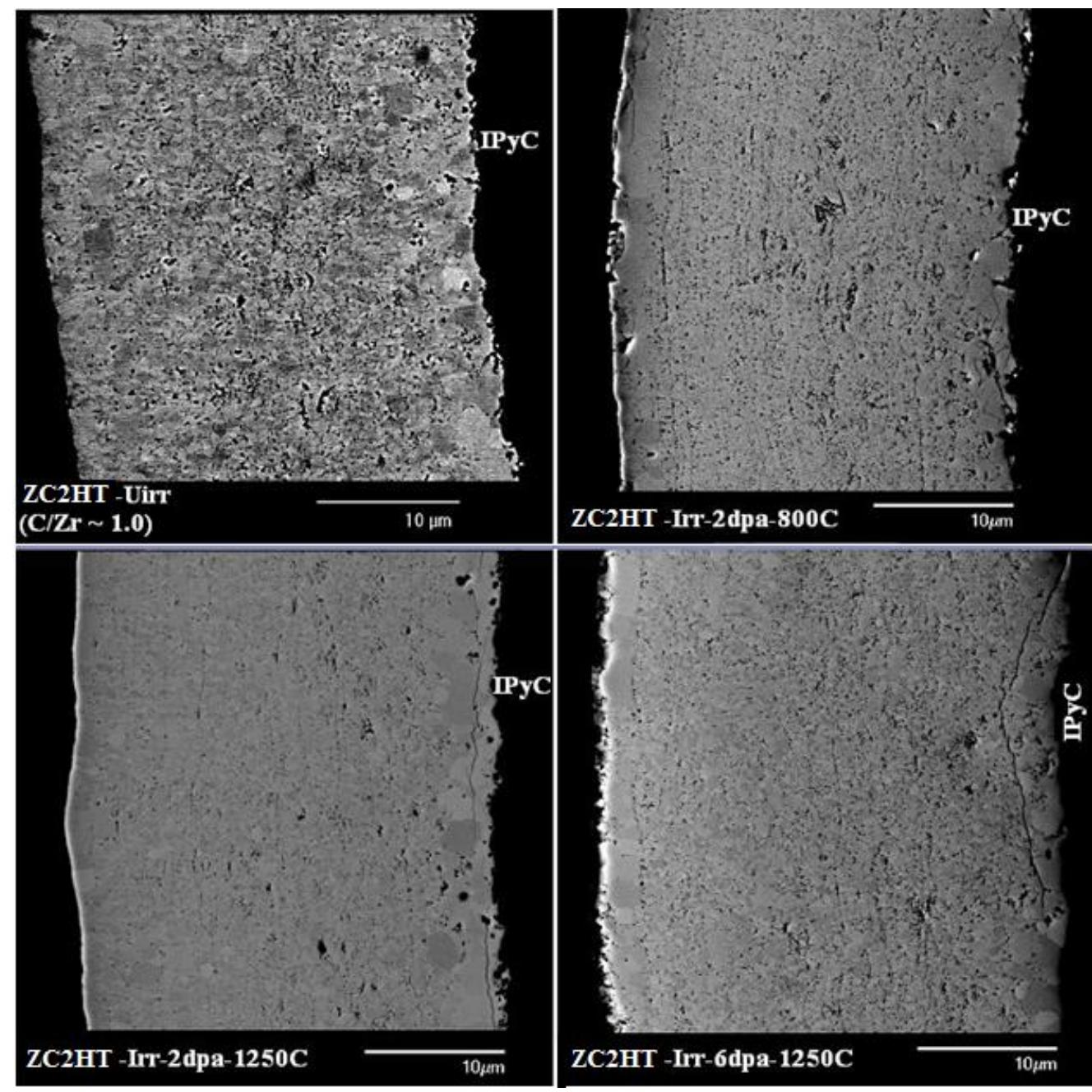

Figure 6. Pre- and post-irradiation microstructure of sample $\mathrm{ZC} 2 \mathrm{HT}$ (C/Zr 1.0) showing modest grain growth at higher irradiation temperatures 


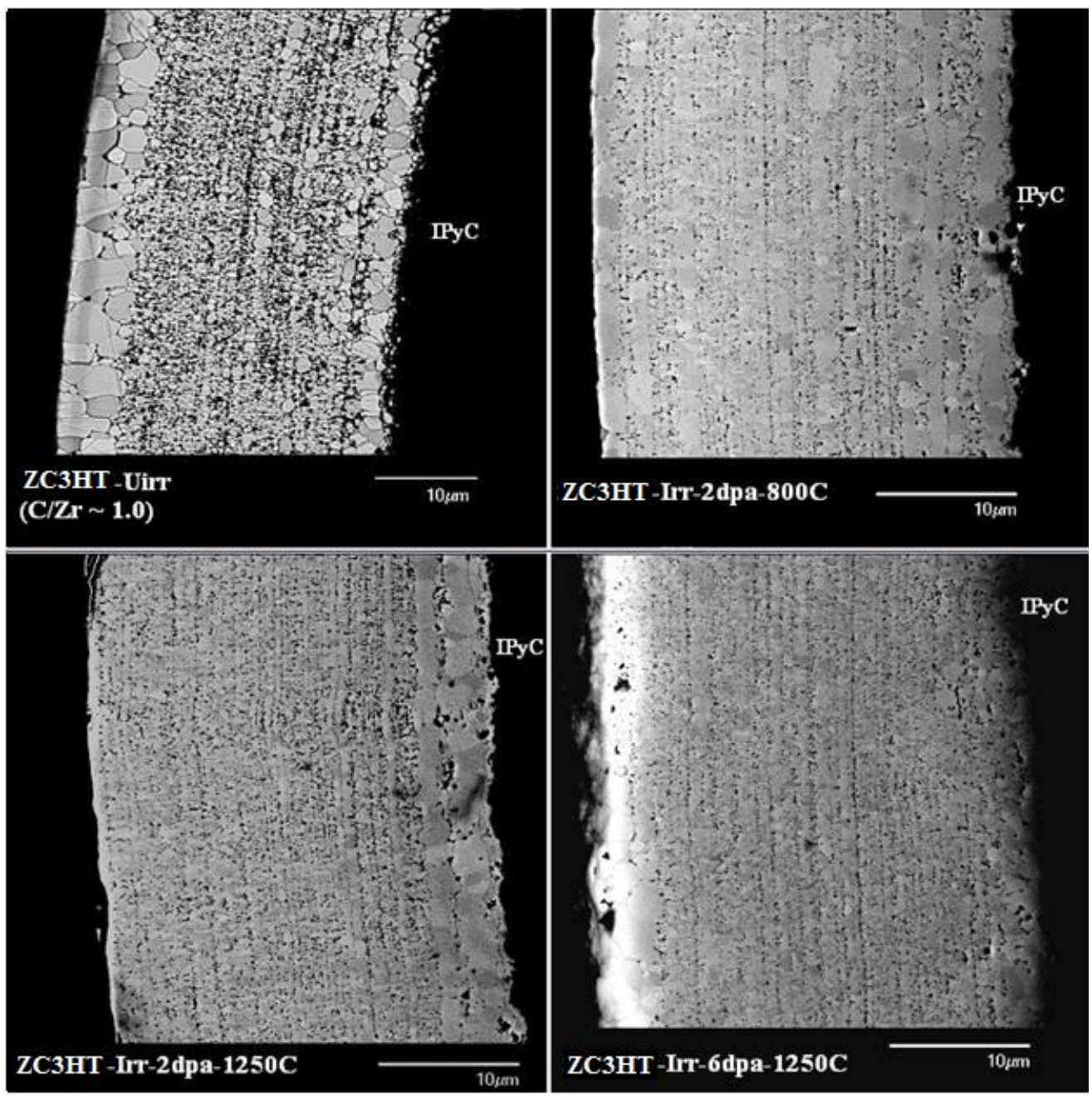

Figure 7. Pre- and post-irradiation microstructure of sample $\mathrm{ZC3HT}(\mathrm{C} / \mathrm{Zr} \sim 1.0)$ with a preserved banded/layered structure 


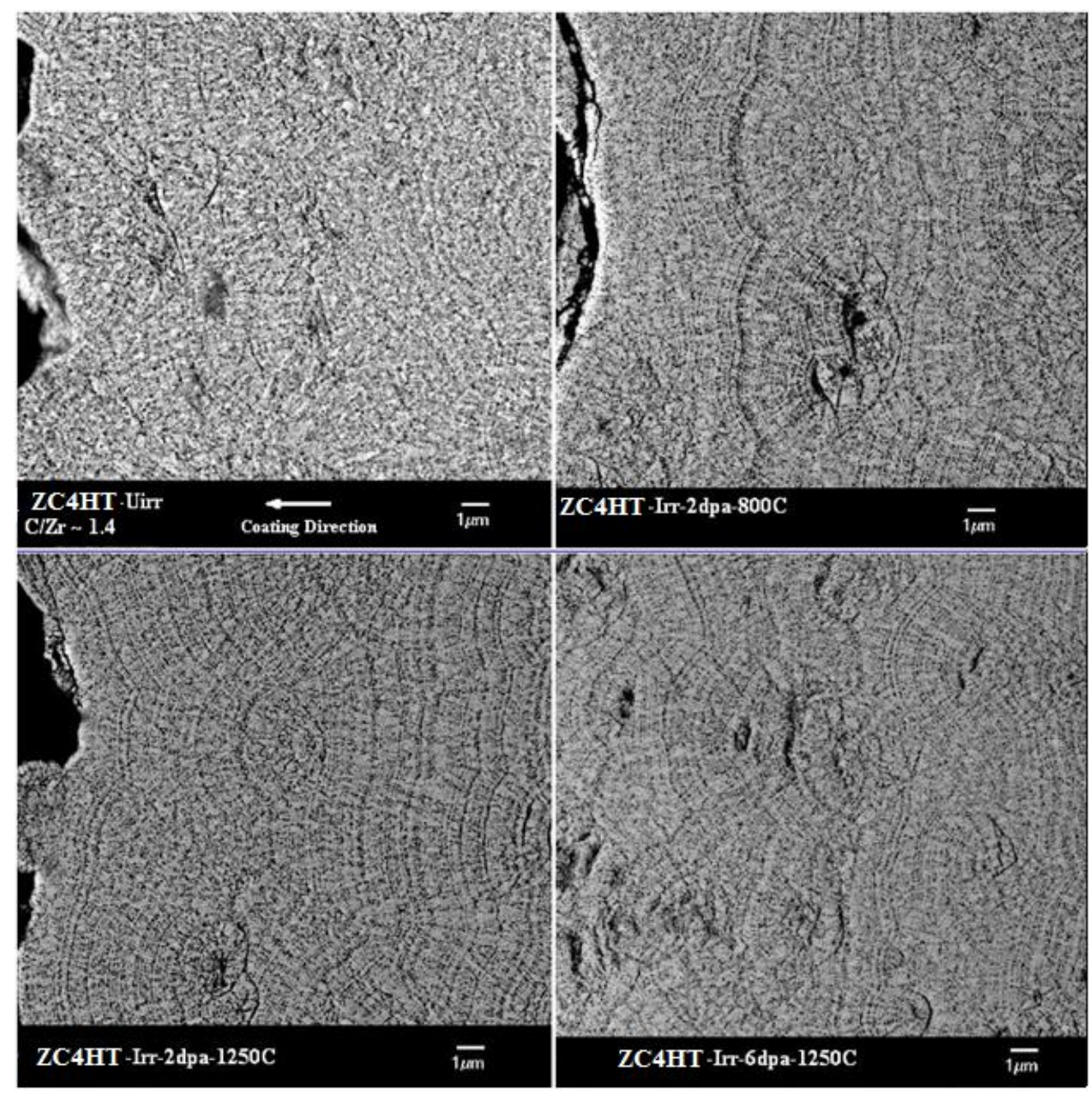

Figure 8. Microstructure of sample ZC4HT (C/Zr 1.4) showing no noticeable change post irradiation 

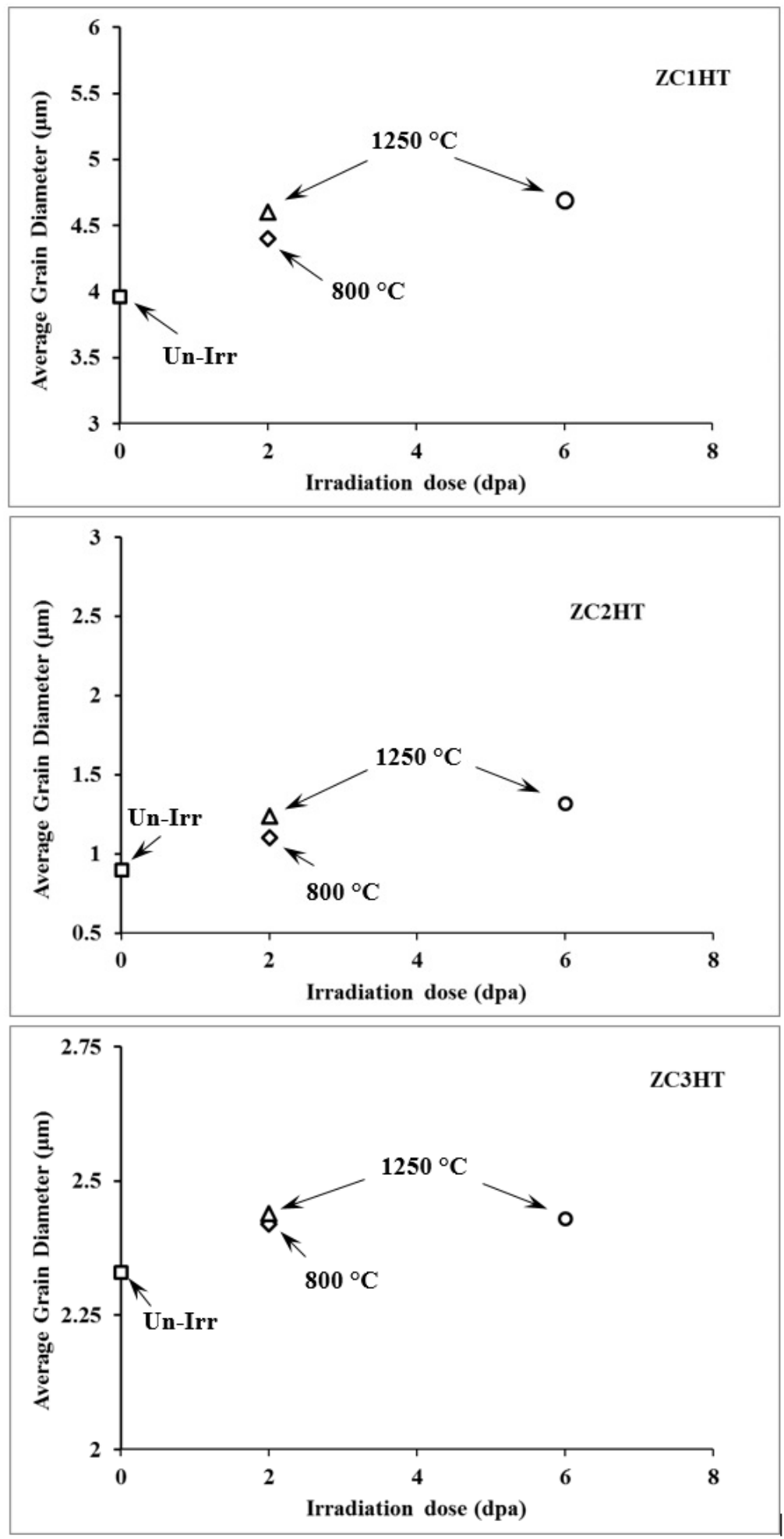

Figure 9. Variation of the AGDs of heat-treated specimens ZC1HT, ZC2HT and ZC3HT with irradiation dose and temperature 

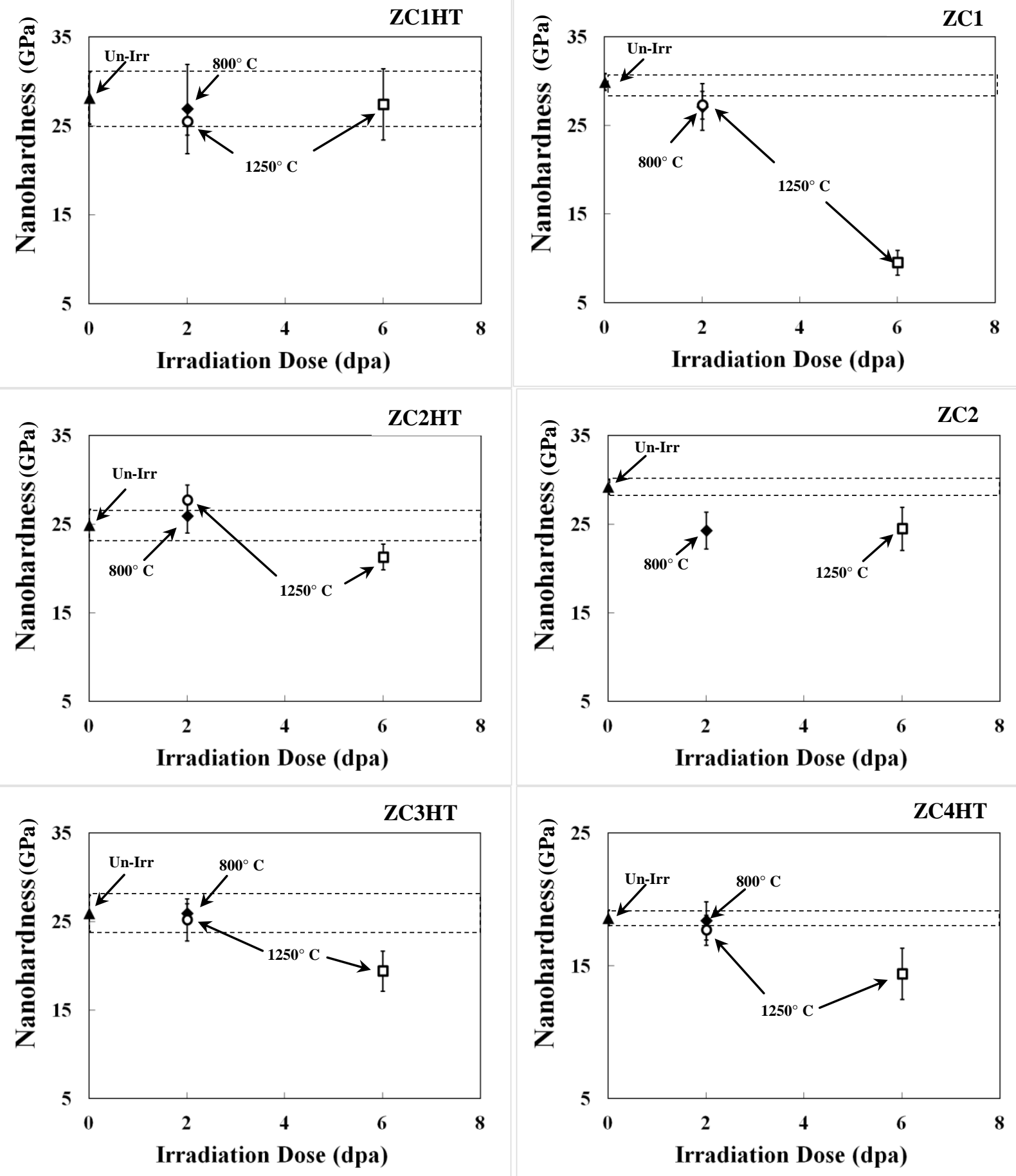

Figure 10. Variation of nano-hardness of CVD ZrC coatings with irradiation dose and temperature 

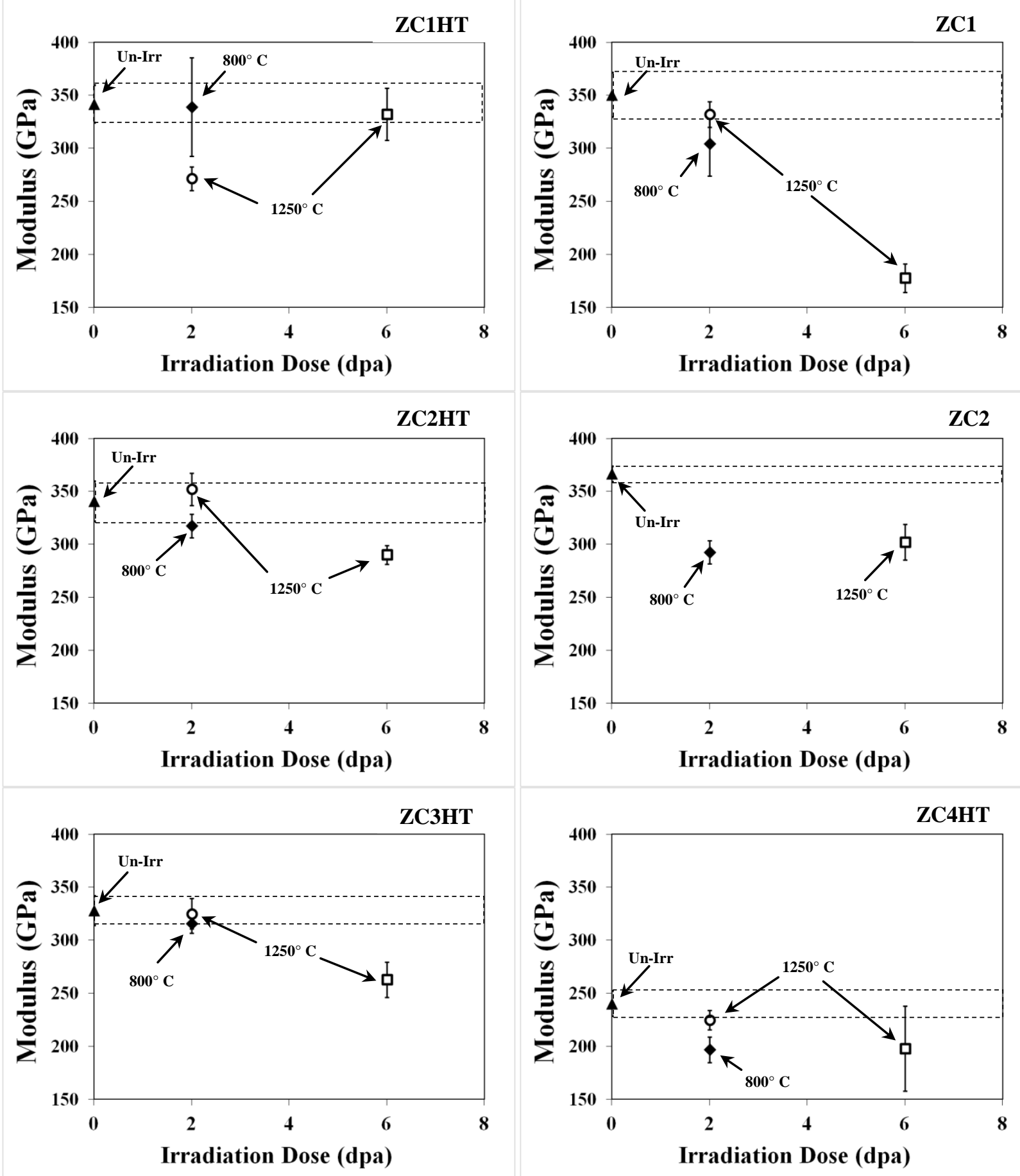

Figure 11. Variation of modulus of $\mathrm{CVD} \mathrm{ZrC}$ coatings with irradiation dose and temperature 


\section{References}

[1] R. M. Versluis, F. Venneri, D. Petti, L. L. Snead, D. McEachern, D, HTR2008 58325, (2008).

[2] G. H. Reynolds, J.C Janvier, J. L. Kaae, J.P. Morelvat, J. Nucl. Mat., 62 (1976), 9.

[3] T. Ogawa, K. Ikawa, K. Fukuda, S. Kashimura, and I. Iwamoto, "Research and Development of ZrC-Coated $\mathrm{UO}_{2}$ Particle Fuel at JAERI"; Conference on Nuclear Fuel Performance, British Nuclear Energy Society, London (1985) 163-169.

[4] K. Minato, T. Ogawa, T. Koya, H. Sekino, T.Tomita, J. Nucl. Mat., 279 (2000), 181.

[5] T. Ogawa, K. Ikawa, High Temp. Sci., 22 (1986), 179.

[6] Y. Katoh, G. Vasudevamurthy, T. Nozawa, L. L. Snead, J. Nucl. Mat, 441 (2013), 718

[7] E.K. Storms, The Refractory Carbides, Academic Press, New York (1967).

[8] Ikawa, J. Less-Common Metals, 27 (1972), 325.

[9] K. Ikawa, K. Iwamoto, J. Nucl. Sc \& Tech., 11 (1974), 263.

[10] K. Ikawa, J. Less-Common Metals, 44 (1976), 207.

[11] J. Aihara, S. Ueta, A. Yasuda, H. Ishibashi, T. Takayama, K. Sawa, Y. Motohash, J. Am. Ceram. Soc., 90, (2007), 3968.

[12] J. Aihara, S. Ueta, A. Yasuda, H. Ishibashi, Y. Mozumi, K. Sawa and Y. Motohash, J. Am. Ceram. Soc., 92, (2009), 197.

[13] J. Aihara, S. Ueta1, A.Yasuda, H.Takeuchi, Y.Mozumi, K. Sawa, Y, Motohashi., Mat. Trans., 50, (2009), 2631.

[14] L. L. Snead, Y. Katoh, S. Kondo, J. Nucl. Mat., 399, (2009) 200.

[15] K. H. Valentine et al., ORNL Report \# 5228 (1977).

[16] G.W. Keilholtz, R.E Moore, Proc. of the Amer. Nucl. Soc. (1969).

[17] G. W. Keilholtz, R. E. Moore, D. A. Dyslin, ORNL Report \# 4390, (1968) 113.

[18] R.A. Andrievskii, Izvestiya Akademii Nauk SSSR, Neorganicheskie Meterialy, 14, (1978) 680.

[19] M. S. Kovalchenko, Y. I. Rogovai, Neorganicheskie Materialy, 9 (1973), 321.

[20] ASTM E112 - 13, Standard Test Methods for Determining Average Grain Size, ASTM publications.

[21] X. M. He, S. Li, L. Hai-Bo, L. Heng-De, J. Vac. Sci. \& Tech. A, Vac. Surf \& Films, 16, (1998). 
[22] D. E. Alexander, G. Was, L. E. Rehn, Nucl. Inst. \& Meth. in Physics Res., 60(1991), 462466

[23] J. T. Maki, D. A. Petti, D. L. Knudson, G. K. Miller, J. Nucl. Mat., 371 (2007), 270-280

[24] R. Darolia, T.F. Archbold, J. Mat. Sci., 11 (1976), 283.

[25] E. A. Little, L. P. Stoter, Effects of Radiation on Materials: $11^{\text {th }}$ Conference, ASTM STP 782, H. R. Brader and J. S. Perrin (eds), ASTM, Philadelphia (1982), 207-233. 